\title{
APLIKASI UREA DAN TANAH BERMIKORIZA PADA PERTUMBUHAN TANAMAN SERTA INFEKSI MIKORIZA PADA AKAR SENGON LAUT (Paraserianthes falcataria (L) Nielson)
}

\author{
(Aplication of Urea and Mycorrhizal soil on growth plant and Micorize infection on Sengon \\ Laut Roots (Paraserianthes falcataria (L) Nielson)) \\ Febri Arif Cahyo Wibowo*, Amir Syarifuddin \\ Jurusan Kehutanan, Fakultas Pertanian Peternakan, Universitas Muhammadiyah Malang \\ *Emai: febriarif14@gmail.com
}

\begin{abstract}
Decrease plant nutrient and water in the land is very alarming. The function of mycorrhizae is very beneficial for plants in forest areas that can be considered critical. Urea which is an instant fertilizer is often used by Indonesian farmers, but it has a negative impact on the soil. The nutrients contained in urea are $45 \%-46 \%$ is Nirogen. The purpose of this research was to study the development of the use of mycorrhizal soils by using urea fertilizer and its interactions, as well as to search for roots infected by mycorrhizae. This research was conducted in the greenhouse at the University of Muhammadiyah Malang conducted from January to February 2017. The design used in the study was a Randomized Complete Block Design (RCBD) with a combination of 16 and 3 replications. Data analysis was done by BNJ ANAVA followed and identification of mycorrhizae in the roots of sea sengon plants. At a dose of 300 grams of mycorrhizae soil is better than other doses. The dose of urea has been effected on sengon laut from the parameters of height and number of leaves. A dose of 1.5 grams of urea produces better plants than other doses. Root infection by mycorrhizae gets the greatest results on the combination of $M 2 P 2$ with a yield of $30 \%$. The type that is in the infected root is Glomus sp. The effect of mycorrhizae occurs only on the root length of plants.
\end{abstract}

Keywords: Mycorrhiza, Root Infection, Sengon Laut, Urea

\section{Abstrak}

Penurunan kualitas unsur hara dan air pada lahan kehutanan sangat memprihatinkan. Fungsi mikoriza yang sangat menguntungkan bagi tanaman pada lahan hutan yang dapat dikatakan kritis. Urea yang merupakan pupuk instan ini sering digunakan oleh para petani Indonesia, namun dapat berdampak negatif terhadap tanah. Unsur hara yang terkandung dalam urea ini 45\%-46\% adalah unsur N. Tujuan dari penelitian ini adalah mengetahui perbandingan pertumbuhan penggunaan tanah bermikoriza dengan penggunaan pupuk urea dan interaksinya, serta mengidentifikasi akar yang terinfekis oleh mikoriza. Penelitian ini dilakukan di green house Universitas Muhammadiyah Malang dilakukan pada bulan Januari-Maret 2017. Rancangan yang digunakan dalam penelitian adalah Rancangan Acak Kelompok Lengkap (RAKL) dengan kombinasi sebanyak 16 dan 3 kali ulangan. Data yang dianalisis menggunakan uji BNJ dan identifikasi mikoriza pada akar tanaman sengon laut. Hasil penelitian menunjukkan bahwa pada dosis 300 gram tanah bermikoriza lebih baik dibandingkan dosis lainnya. Dosis urea sangat mempengaruhi pertumbuhan sengon laut dari parameter tinggi dan jumlah daun. Dosis urea sebanyak 1,5 gram menghasilkan tanaman yang lebih baik dibandingkan dosis lainnya. Infeksi akar oleh mikoriza mendapatkan persentase terbesar pada kombinasiM2P2 yaitu 30\%. Jenis yang terdapat pada terinfeksinya akar yakni jenis Glomus sp. Pengaruh mikoriza ini terjadi hanya pada panjang akar tanaman saja.

Kata Kunci: Mikoriza, Sengon Laut, Infeksi Akar, Urea 


\section{PENDAHULUAN}

Lahan hutan yang sering ditemukan di lapang dengan kondisi tekstur dan sifat tanah dalam keadaan krisis akan unsur hara $\mathrm{N}$ dan $\mathrm{Mg}$ yang rendah (Yamani, 2012) salah satu penelitian di Desa Kudung karang terjadi pengurangan air dari dampak perubahan iklim (Amalia dan Sugiri, 2014). Dampak penggunaan bahan kimia dalam kegiatan pemenuhan NPK menyebabkan peningkatan penggunaan bahan kimia sebagai pengganti unsur hara seperti urea. Masyarakat yang menggunakan pupuk kimia tidak menyadari dampak negatif pupuk kimia tersebut. Pupuk kimia akan mengikat air (hidroskopis), sehingga tanah akan kekurangan air dan mengalami kekeringan. Penggunaan pupuk alami lebih baik dari pada yang berbahan kimia, seharusnya masyarakat mengubah pola pikir praktis dengan menggunakan pupuk organik, yakni dengan penggunaan bahan yang sudah tersedia di alam secara alamiah. Mengubah pola pikir masyarakat untuk menggunakan bahan organik tidak mudah akibat kebiasaan masyarakat yang menggunakan pupuk kimia praktis, sehingga terjadi dampak negatif. Perlu dilakukan peningkatan unsurhara secara alamiah.

Penggunaan mikoriza pada lahan yang krisis akan unsur hara dan kurangnya air dalam tanah sangat membantu pertumbuhan tanaman. Fungsi mikoriza yang sangat menguntungkan bagi tanaman dalam keadaan lahan hutan yang dapat dikatakan kritis (Talanca, 2015). diperlu penerapan pada lahan kritis agar mikoriza dapat menginfeksi semua tanaman hutan, sehingga dengan simbiosis antara akar dengan mikoriza dapat menguntungkan tanaman kehutanan dalam penyediaan unsur hara dan air yang kurang tersedia pada lahan hutan.

Selain dampak negatif, terdapat positifnya di mana urea ini dapat memenuhi unsur hara NPK. Unsur hara yang terkandung dalam urea ini memang $45 \%-46 \%$ adalah unsur N (Nainggolan dkk, 2009). Hal ini sangat menguntungkan bagi tanaman yang memang membutuhkan unsur $\mathrm{N}$ agar daun, batang dan lain-lain bertumbuh dan berkembang dengan baik (Fahmi $\mathrm{dkk}, 2010)$. Tujuan dari penelitian ini adalah mengetahui pengaruh perlakuan dosis tanah bermikoriza dan dosis urea terhadap pertumbuhan serta infeksi akar semai sengon laut (Paraserianthes falcataria (L) Nielson).

\section{METODE PENELITIAN}

\section{Tempat Dan Waktu}

Penelitian ini dilakukan di green house Universitas Muhammadiyah Malang dengan ketinggian tempat \pm 540 mdpl dengan curah hujan rata-rata 1.833 $\mathrm{mm} /$ tahun dan penelitian ini dilakukan pada bulan Januari - Maret 2017.

\section{Rancangan Penelitian}

Rancangan yang digunakan dalam penelitian adalah Rancangan Acak Kelompok Lengkap (RAKL) dengan kombinasi dair perlakuan M (tanah bermikoriza kontrol, 100gram, 200gram dan 300gram) dengan $\mathrm{P}$ (dosis urea kotrol, 0,5gram, 1gram dan 1,5gram) sehingga memiliki 16 kombinasi dan dalam penelitian dilakukan ulangan 
sebanyak 3 kali, sesuai dengan perhitungan dalam menentukan ulangan dengan rumus $(\mathrm{t}-1)(\mathrm{r}-1) \geq 15$.

Kombinasi yang didapat adalah: M0P0, M1P0, M2P0, M3P0, M0P1, M1P1, M2P1, M3P1, M0P2, M1P2, M2P2, M3P2, M0P3, M1P3, M2P3, $\mathrm{M} 3 \mathrm{P} 3$ berdasarkan kombinasi dari perlakuan tanah bermikoriza dan dosis urea.

Dalam menganalisis data yang digunakan uji BNJ. Parameter yang diamati adalah tinggi tanaman, jumlah daun, identifikasi infeksi oleh mikoriza.

\section{Identifikasi Akar yang Terinfeksi Mikoriza}

\section{1) Pewarnaan akar}

Sukarno (1999) dalam Nirmalasari (2005), mengemukakan bahwa untuk melihat ada tidaknya asosiasi antara cendawan dan sampel akar dilakukan pewarnaan akar dengan langkah-langkah sebagai berikut:

a. Akar dari setiap umur tanaman sengon laut dicuci dengan air sampai bersih, kemudian direndan dengan larutan $\mathrm{KOH} 10 \%$ selama 24 jam untuk membersihkan akar, bilas dengan akuades beberapa kali. Jika akar belum berwarna putih maka direndam sebentar dalam $\mathrm{H}_{2} \mathrm{O}_{2} \quad 10 \%$ dan NaCL $3 \%$ sampai memutih dan dibilas dengan air sampai bersih.

b. Setelah perlakuan a, akar direndam dalam larutan HCL 2\% selama 24 jam

c. Kemudian akar diwarnai dengan merendamnya dalam larutan Metil Blue (MB) dan xilon selama 24 jam. Setelah itu derendam kembali dalam xilon agar permukaan akar bersih dari pewarna metil blue. d. Potongan akar dapat diamati di bawah mikroskop digital dengan perbesaran 100-400 kali.

\section{2) Persentase Infeksi Akar oleh Mikoriza}

Untuk mengetahui persentasi akar sengon laut yang terinfeksi oleh mikoriza dengan melakukan perhitungan persentase infeksi akar rumus Philip \& Haymen (1970) yang telah dimodifikasi dengan teknik Koske dan Gemma (1989) dalam Windyaningrum (2008). Dengan mengambil 10 sampel akar yang sudah diidentifikasi dalam pewarnaan akar diatas dengan ukuran panjang akar $1 \mathrm{~cm}$. dari semua sampel yang sudah dilakukan pewarnaan, dilihat dibawah mikroskop untuk mengetahui dari 10 sampel akar yang terinfeksi dan yang tidak terinfeksi oleh mikoriza. Pengambilan 10 sampel akar ini dilakukan dengan random atau acak.

Infeksi Akar :

Jumlah Akar yang Terinfeksi x 100\%

Jumlah Akar yang Dipotong

HASIL DAN PEMBAHASAN

\section{Tinggi Tanaman}

Perlakuan urea berpengaruh sangat nyata terhadap rata-rata tinggi tanaman sengon laut. Pengaruh dari perlakuan mikoriza tidak mempengaruhi tinggi tanaman tersebut. Hasil dari Tabel 1, menunjukkan bahwa pengaruh yang diberikan oleh urea dari minggu pertama hingga akhir mengalami pengaruh yang sangat nyata.

Perlakuan mikoriza pada sengon laut dalam penelitian memberikan pertumbuhan yang tidak teratur dari setiap minggunya. Pertumbuhan tinggi tanaman yang paling tinggi pada minggu 
keempat dengan perlakuan M4 sebesar 4,45. Pertumbuhan terendah pada parameter tinggi dengan perlakuan mikoriza yakni, M1 pada minggu pertama hanya rerata tinggi sebesar 1,80 .

Tabel 1. Rata-rata pertambahan tinggi tanaman sengon laut (Paraseriantes falcataria (L) Nielson) dari perlakuan dosis tanah bermikoriza (M) dan penggunaan dosis pupuk urea $(\mathrm{P})$. (Average growth of sengon plants (Paraserianthes falcataria (L) Nielson) from treatment of doses of bermororiza $(M)$ and doses of urea fertilizer $(P)$ )

\begin{tabular}{ccccccccc}
\hline \multirow{2}{*}{ Perlakuan } & \multicolumn{7}{c}{ Rata-rata nilai tengah tinggi(cm)/minggu } \\
\cline { 2 - 9 } & 1 Mst & 2 Mst & 3 Mst & 4 Mst & $\mathbf{5 ~ M s t}$ & $\mathbf{6 ~ M s t}$ & $\mathbf{7 ~ M s t}$ & $\mathbf{8 ~ M s t}$ \\
\hline M0 & $1,83 \mathrm{a}$ & $3,78 \mathrm{a}$ & $3,56 \mathrm{a}$ & $4,16 \mathrm{a}$ & $3,44 \mathrm{a}$ & $3,44 \mathrm{a}$ & $3,44 \mathrm{a}$ & $3,44 \mathrm{a}$ \\
M1 & $1,80 \mathrm{a}$ & $3,68 \mathrm{a}$ & $3,72 \mathrm{a}$ & $4,22 \mathrm{a}$ & $3,60 \mathrm{a}$ & $3,60 \mathrm{a}$ & $3,60 \mathrm{a}$ & $3,60 \mathrm{a}$ \\
M2 & $1,86 \mathrm{a}$ & $3,99 \mathrm{a}$ & $3,91 \mathrm{a}$ & $4,40 \mathrm{a}$ & $3,74 \mathrm{a}$ & $3,79 \mathrm{a}$ & $3,78 \mathrm{a}$ & $3,78 \mathrm{a}$ \\
M3 & $1,89 \mathrm{a}$ & $4,29 \mathrm{a}$ & $3,24 \mathrm{a}$ & $4,54 \mathrm{a}$ & $4,17 \mathrm{a}$ & $4,18 \mathrm{a}$ & $4,08 \mathrm{a}$ & $4,12 \mathrm{a}$ \\
P0 & $1,51 \mathrm{a}$ & $2,40 \mathrm{a}$ & $2,35 \mathrm{a}$ & $2,90 \mathrm{a}$ & $2,67 \mathrm{a}$ & $2,72 \mathrm{a}$ & $2,69 \mathrm{a}$ & $2,74 \mathrm{a}$ \\
P1 & $1,62 \mathrm{~b}$ & $3,76 \mathrm{~b}$ & $3,94 \mathrm{~b}$ & $3,89 \mathrm{~b}$ & $3,08 \mathrm{~b}$ & $3,10 \mathrm{~b}$ & $3,07 \mathrm{~b}$ & $3,09 \mathrm{~b}$ \\
P2 & $2,12 \mathrm{c}$ & $4,42 \mathrm{c}$ & $4,56 \mathrm{c}$ & $5,15 \mathrm{c}$ & $4,23 \mathrm{c}$ & $4,24 \mathrm{c}$ & $4,19 \mathrm{c}$ & $4,15 \mathrm{c}$ \\
P3 & $2,13 \mathrm{~d}$ & $5,16 \mathrm{~d}$ & $4,58 \mathrm{~d}$ & $5,38 \mathrm{~d}$ & $4,97 \mathrm{~d}$ & $4,95 \mathrm{~d}$ & $4,95 \mathrm{~d}$ & $4,97 \mathrm{~d}$ \\
\hline
\end{tabular}

Keterangan: Mst: minggu setelah tanam.

Perlakuan urea, pengaruh sangat nyata terhadap tinggi tanaman pada minggu pertama hingga terakhir. Mengalami penurunan pertambahan tinggi pada minggu keempat hingga minggu kedelapan. Pertumbuhan tinggi terbesar yakni pada minggu keempat dengan nilai sebesar 5,38. Pertumbuhan terendah yakni pada perlakuan P0 dengan nilai sebesar 1,51.

Menurut Raharjo dan Pribadi (2010), bahwa penggunaan pupuk urea yang semakin tinggi dosisnya berpengaruh nyata meningkatkan pertumbuhan tanaman (tinggi tanaman, jumlah anakan, jumlah rimpangan induk, bobot rimpang kering dan bobot rimbang batang+daun/rumpun). Warna daunnya lebih hijau gelap dan pertumbuhannya pada tinggi tanaman lebih tinggi pada tanaman yang dipupuk urea berdosis 300 $\mathrm{kg} / \mathrm{ha}$.

\section{Jumlah Daun Tanaman}

Interaksi antara perlakukan dosis urea dan tanah bermikoriza tidak mempengaruhi jumlah daun yang gugur pada setiap minggunya. Namun nilai paling besar pada interaksi perlakuan diatas yakni pada M3P3 sebesar 2,07 helai pada minggu ke-5, sedangkan nilai rata-rata terendah yakni pada MOP0 pada minggu ke-6 sebesar 0,40 helai. Daun akan mengalami gugur daun pada saat tanaman mengalami pertumbuhan tinggi. Berdasarkan Tabel 3, perlakuan urea memiliki pengaruh terhadap jumlah daun, sedangkan mikoriza tidak berpengaruh. 
Tabel 2. Rata-rata pertambahan jumlah daun tanaman sengon laut ( $P$. falcataria (L) Nielson) dari perlakuan dosis tanah bermikoriza (M) dan penggunaan dosis pupuk urea $(\mathrm{P})$. (The average increase in the number of leaves of Sengon Laut (P. falcataria (L) Nielson) from the treatment of the doses of mycorrhizal soil $(M)$ and doses of urea fertilizer $(P))$

\begin{tabular}{ccccccccc}
\hline \multirow{2}{*}{ Perlakuan } & \multicolumn{7}{c}{ Rata-Rata Nilai Tengah Jumlah Daun/minggu (helai) } \\
\cline { 2 - 9 } & 1 Mst & 2 Mst & 3 Mst & 4 Mst & 5 Mst & 6 Mst & 7 Mst & 8 Mst \\
\hline M0 & $2,65 \mathrm{a}$ & $3,10 \mathrm{a}$ & $3,25 \mathrm{a}$ & $3,70 \mathrm{a}$ & $3,55 \mathrm{a}$ & $2,45 \mathrm{a}$ & $3,35 \mathrm{a}$ & $3,55 \mathrm{a}$ \\
M1 & $2,60 \mathrm{a}$ & $3,30 \mathrm{a}$ & $3,20 \mathrm{a}$ & $3,75 \mathrm{a}$ & $3,45 \mathrm{a}$ & $2,71 \mathrm{a}$ & $3,60 \mathrm{a}$ & $3,75 \mathrm{a}$ \\
M2 & $2,78 \mathrm{a}$ & $3,80 \mathrm{a}$ & $3,70 \mathrm{a}$ & $3,60 \mathrm{a}$ & $3,95 \mathrm{a}$ & $3,28 \mathrm{a}$ & $4,10 \mathrm{a}$ & $4,25 \mathrm{a}$ \\
M3 & $2,50 \mathrm{a}$ & $3,90 \mathrm{a}$ & $3,90 \mathrm{a}$ & $4,00 \mathrm{a}$ & $4,05 \mathrm{a}$ & $3,23 \mathrm{a}$ & $4,20 \mathrm{a}$ & $4,35 \mathrm{a}$ \\
P0 & $1,90 \mathrm{a}$ & $2,25 \mathrm{a}$ & $2,25 \mathrm{a}$ & $2,70 \mathrm{a}$ & $2,35 \mathrm{a}$ & $1.34 \mathrm{a}$ & $2,30 \mathrm{a}$ & $2,25 \mathrm{a}$ \\
P1 & $2,20 \mathrm{~b}$ & $3,15 \mathrm{~b}$ & $3,00 \mathrm{~b}$ & $3,35 \mathrm{~b}$ & $3,20 \mathrm{~b}$ & $2,65 \mathrm{~b}$ & $3,55 \mathrm{~b}$ & $3,55 \mathrm{~b}$ \\
P2 & $2,85 \mathrm{c}$ & $4,25 \mathrm{c}$ & $4,00 \mathrm{c}$ & $4,55 \mathrm{c}$ & $4,30 \mathrm{c}$ & $3,40 \mathrm{c}$ & $4,60 \mathrm{c}$ & $4,55 \mathrm{c}$ \\
P3 & $3,55 \mathrm{~d}$ & $4,45 \mathrm{~d}$ & $4,80 \mathrm{~d}$ & $4,45 \mathrm{~d}$ & $5,15 \mathrm{~d}$ & $4,28 \mathrm{~d}$ & $4,80 \mathrm{~d}$ & $5,55 \mathrm{~d}$ \\
\hline
\end{tabular}

Keterangan: Mst: minggu setelah tanam.

Semakin tinggi perlakuan tidak juga memberikan hasil semakin banyak jumlah daun yang tumbuh pada setiap satu minggu pada perlakuan mikoriza. Pada minggu pertama, rerata jumlah daun M0 lebih besar dibandingkan dengan M1 pada minggu pertama, ketiga dan kelima. Perlakuan mikoriza paling banyak pertumbuhan jumlah daunnya pada M3 pada minggu kedelapan dengan jumlah daun sebanyak 4,35 helai. Pertambahan jumlah daun terendah pada M1 pada minggu pertama dengan jumlah daun sebanyak 2,60 helai. Perlakuan urea dengan rerata jumlah daun yang tumbuh terbanyak yakni pada P3 pada minggu kedelapan dengan 5,55 helai. Hasil terendah yakni pada P0 pada minggu pertama dengan 1,90 helai.

\section{Persentase Infeksi Akar}

Glomus adalah jenis FMA yang mempunyai penyebaran paling dominan, karena 10 dari 14 spesies yang didapatkan adalah tipe Glomus. Pada tanah Andosol di KP Gunung Putri didapatkan jenis Glomus dan Acaulospora, sedangkan pada tanah Latosol/Inceptisols terdapat perbedaan jenis FMA dari 2 lokasi penelitian, yaitu jenis Glomus dan Acaulospora di KP Cicurug, dan 3 jenis FMA, yaitu Glomus, Acaulospora, dan Scutellospora di KP Sukamulya. Tingginya frekuensi kehadiran spora FMA tipe Glomus ini mungkin berhubungan dengan genus Glomus yang sangat banyak dibandingkan jenis lain. Dari 172 jenis FMA yang sudah diidentifikasi diketahui Glomus adalah jenis yang paling dominan (52,3\%), diikuti Acaulospora (20,9\%), Scutellospora (16,9\%), Gigaspora (4,7\%), Entrophospora (2,3\%), Archaeospora (1,7\%), dan Paraglomus $(1,2 \%)$ menurut (INVAM, 2008) dalam Hartoyo (2011). 
Table 3. Persentase infeksi akar tanaman sengon laut (P. falcataria (L) Nielson) oleh mikoriza. (Percentage of root infection of Sengon Laut (P. falcataria (L) Nielson) by mycorrhiza)

\begin{tabular}{cc}
\hline Perlakuan & Persentase Infeksi Akar (\%) \\
\hline M1P0 & $10 \%$ \\
M2P0 & $0 \%$ \\
M3P0 & $10 \%$ \\
M1P1 & $0 \%$ \\
M2P1 & $10 \%$ \\
M3P1 & $10 \%$ \\
M1P2 & $10 \%$ \\
M2P2 & $30 \%$ \\
M3P2 & $20 \%$ \\
M1P3 & $0 \%$ \\
M2P3 & $10 \%$ \\
M3P3 & $20 \%$ \\
\hline
\end{tabular}

Keterangan :

M1P0= Tanah bermikoriza sebanyak 100 gram dan Pupuk urea 0 gram, M2P0= Tanah bermikoriza sebanyak 200 gram dan Pupuk urea 0 gram, M3P0= Tanah bermikoriza sebanyak 300 gram dan Pupuk urea 0 gram, M1P1= Tanah bermikoriza sebanyak 100 gram dan Pupuk urea 0.5 gram, M2P1= Tanah bermikoriza sebanyak 200 gram dan Pupuk urea 0.5 gram, M3P1= Tanah bermikoriza sebanyak 300 gram dan Pupuk urea 0.5 gram, M1P2= Tanah bermikoriza sebanyak 100 gram dan Pupuk urea 1 gram, M2P2= Tanah bermikoriza sebanyak 200 gram dan Pupuk urea 1 gram, M3P2= Tanah bermikoriza sebanyak 300 gram dan Pupuk urea 1 gra m, M1P3= Tanah bermikoriza sebanyak 100 gram dan Pupuk urea 1.5 gram, M2P3= Tanah bermikoriza sebanyak 200 gram dan Pupuk urea 1.5 gram, $\mathrm{M} 3 \mathrm{P} 3=$ Tanah bermikoriza sebanyak 300 gram dan Pupuk urea 1.5 gram

Semakin besar dosis mikoriza ynag diberikan belum menentukan persentase infeksi akar yang besar. Dari Tabel 6 ini dibuktikan bahwa kombinasi yang baik dengan persentase infeksi akar terbesar yakni pada M2P2 sebesar 30\%, sedangkan yang tidak terinfeksi oleh mikoriza pada kombinasi M2P0 dan M1P3 dengan infeksi akan $0 \%$.

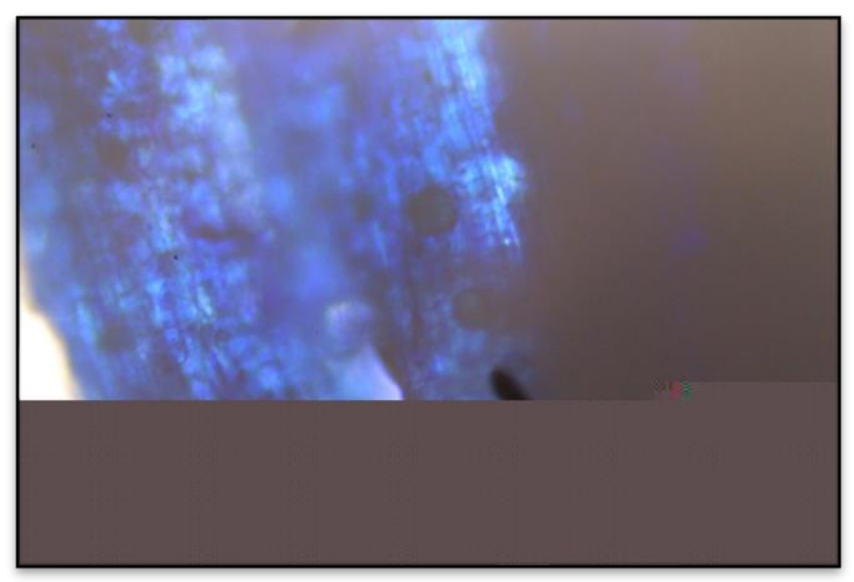

Gambar. 2. Infeksi akar oleh mikoriza pada sengon laut (Root infection by mycorrhizae in Sengon Laut) 
Pengujian ini untuk mengetahui berapa persen mikoriza yang menginfeksi akar tanaman, selain itu untuk mengetahui bentuk dari mikoriza yang menginfeksi akar. Gambar 2 yang menunjukkan bahwa, bentuk mikoriza yang peneliti amati berbentuk bulat dan membentuk koloni di daerah lain dengan jarak yang tidak terlalu jauh. Bentuk bulat tersebut merupakan arbuskula, mengenai hifa dari mikoriza ini tidak begitu terliha akibar terlalu pekatnya dalam pewarnaan yang dilakukan oleh peneliti dan menyebabkan warna akar terlalu biru, namun ketika peneliti melihat di mikroskop dengan perbesaran 100x, mikoriza tersebut terlihat terdapatnya hifa yang merupakan alat yang dimiliki oleh semu jenis mikoriza yang biasanya menginfeksi akar tanaman. Mikoriza ini bisa menginfeksi 99\% tanaman.

\section{KESIMPULAN}

Interaksi dari kombinasi perlakuan tanah bermikoriza dan dosis urea tidak berpengaruh signifikan terhadap tinggi dan jumlah daun tanaman sengon laut, namun secara perlakuan dosis urea berpengaruh terhadap tinggi dan daun. Infeksi akar oleh mikoriza hasil persentase terbesar pada kombinasi M2P2 dengan hasil 30\%.

\section{DAFTAR PUSTAKA}

Amalia, Bunga Irada dan Sugiri, Agung. 2014. Ketersediaan Air Bersih Dan Perubahan Iklim: Studi Krisis Air Di Kedungkarang Kabupaten Demak. Jurnal Teknik P WK Volume 3 Nomor 22014 Online : http://ejournals1.undip.ac.id/index.php/pwk
Fahmi, Arifin; Syamsundin; Utami, Sri Nuryani H dan Radjagukguk, Bostang. 2010. Pengaruh Interaksi Hara Nitrogen Dan Fosfor Terhadap Pertumbuhan Tanama Njagung (Zea Maysl) Pada Tanah Regosol Dan Latosol. Berita Biologi 10 (3)- Desember2010

Hartoyo, Budi $\quad d k k$. 2011. Keanekaragaman Fungi Mikoriza Arbuskula (FMA) pada Rizosfer Tanaman Pagagan (Centella asiatica (L) Urban). Jurnal littri. Volume 17, No. 1. Diakses tanggal 04 April 2015.

Nainggolan, Ganda Darmono; Suwardi dan Darmawan. 2009. Pola Pelepasan Nitrogen Dari Pupuk Tersedia Lambat (Slow Release Fertilizer) Urea-Zeolit-Asam Humat. Jurnal Zeolit Indonesia Vol 8 No. 2. November 2009

Nirmalasari. 2005. Keberadaan Cendawan Mikoriza Arbuskula (CMA) Pada Tegakan Durian (Durio zibethinus Murr). Skripsi Fakultas Kehutanan UNTAN.Pontianak.

Phyllip JM, Hayman DS. 1970. Improved procedures for clearing roots and staining parasitic and vesicular-arbuscular mycorrhizae fungi for rapid assessment of infection. Trans Brit Mycol Soc. 55:158-161

Raharjo, Mono dan Ekwasita R. P. 2010. Pengaruh Pupuk UREA, SP36, dan $\mathrm{KCl}$ terhadap Pertumbuhan dan Produksi Teemulawak (Curcuma xanthorhiza Roxb). Jurnal Littri. Volume. 16, No. 3. Diakses tanggal 01 April 2015.

Talancar, A. Haris. 2015. Manfaat Mikoriza Vesikular-Arbuskular (Mva)Terhadap Pertumbuhan Dan 
JURNAL TENGKAWANG (2020)

Vol. 10 (2): 89 - 96

Pengendalian Penyakit Tanaman.

Prosiding Seminar Nasional

Serealia

Windyaningrum, Ratih. 2008. Pengaruh

Pemberian Mikoriza (CMA),

Asam Humik serta

Mikroorganisme Tanah Potensial terhadap Pertumbuhan dan Produksi Setaria splendida Stapf pada Latosol dan Tailing Tambang Emas. Skripsi. Bodgor: Fakultas Peternakan, Institut Pertanian Bogor.

Yamani, Ahmad. 2012. Analisis Kadar Hara Makro Tanah Pada Hutan Lindung Gunung Sebatung Di Kabupaten Kotabaru. Jurnal Hutan Tropis Volume 12 No. 2 September 2012 